\title{
The artificial anal sphincter
}

\author{
John Christiansen MD FRCS
}

J Christiansen. The artificial anal sphincter. Can J Gastroenterol 2000;14(Suppl D):152D-154D. The artificial anal sphincter as treatment for end stage anal incontinence was first described in 1987. Published series concern a total of 42 patients, with a success rate of approximately $80 \%$. Infection has been the most serious complication, but a number of technical complications related to the device have also occurred and required revisional procedures in $40 \%$ to $60 \%$ of the patients. The artificial anal sphincter may be used for the same indications as dynamic graciloplasty except in patients with a previously irradiated or severely scarred perineum.

Key Words: Anal incontinence; Artifical anal sphincter; Neurological disease

\section{Sphincter anal artificiel}

RÉSUMÉ : La pose d'un sphincter anal artificiel pour le traitement de l'incontinence anale en phase terminale a été décrite pour la première fois en 1987. Des séries publiées portant sur un total de 42 patients font état d'un taux de réussite d'environ $80 \%$. Les infections se sont avérées la complication la plus sérieuse, mais des complications techniques liées au dispositif ont également nécessité une réintervention dans 40 à $60 \%$ des cas. Les indications de la pose d'un sphincter anal artificiel sont les mêmes que celles de la graciloplastie dynamique, sauf chez les patients dont le périnée a déjà été irradié ou est grandement cicatrisé.
$\mathrm{O}$ bstetric and iatrogenic traumatic anal incontinence can be treated successfully in approximately $80 \%$ of the patients by reconstructing the external anal sphincter and pelvic floor muscles (1-3). The success rate for treatment of obstetric tears seems, however, to depend on the age of the patient, with poorer results achieved in women over the age of 40 years (4). In patients with idiopathic incontinence treated by postanal repair, acceptable long term results are only obtained in a moderate fraction of patients, probably not more than $25 \%$ (5). Consequently, a group of patients, which include those with severe destruction of the external anal sphincter and those in whom local sphincter repair has failed, need other surgical treatment modalities. These include transposition of skeletal muscle around the anal canal, usually combined with the implantation of a neurostimulator $(6,7)$; implantation of stimulating electrodes around the sacral nerves S2-S4 that innervates the external anal sphincter and pelvic floor muscles; and implantation of an artificial anal sphincter. The present review deals with the latter modality, first described in 1987 (8), which also is applicable to patients who are incontinent due to neurological diseases.

\section{DESCRIPTION OF THE ARTIFICIAL ANAL SPHINCTER AND SURGICAL TECHNIQUE}

The artificial sphincter used in the studies referred to in this review is made of silicone and consists of three parts: a cuff that is placed around the anal canal, a pressure regulating balloon and a pump (Figure 1).

The patient is placed in the lithotomy position. The perianal approach may be through two incisions at 3 and 9 o'clock or through one curved incision anteriorly. A tunnel is created around the anal canal by blunt dissection, and pulleys are created posteriorly using the anococcygeal raphe and anteriorly by using the raphe of the transversus perinei muscle when possible. This ensures that the cuff remains in the correct position around the anal canal. The optimal position is at the level of the anorectal junction. Cuff length is measured precisely to obtain the best fit using a specially designed cuff sizer placed in the tunnel around the anal canal.

This mini-review was prepared from a presentation made at the 1998 World Congress of Gastroenterology, Vienna, Austria, September 6 to 11, 1998 Department of Surgical Gastroenterology D, Herlev Hospital, University of Copenhagen, Copenhagen, Denmark

Correspondence and reprints: Dr John Christiansen, Department of Surgical Gastroenterology D, Herlev Hospital, University of Copenhagen,

DK-2730 Herlev, Copenhagen, Denmark. Telephone +45-44-88-36-00, fax +45-44-88-44-89, e-mail jochr@herlevhosp.kbhamt.dk Received for publication May 13, 1999. Accepted May 14, 1999 


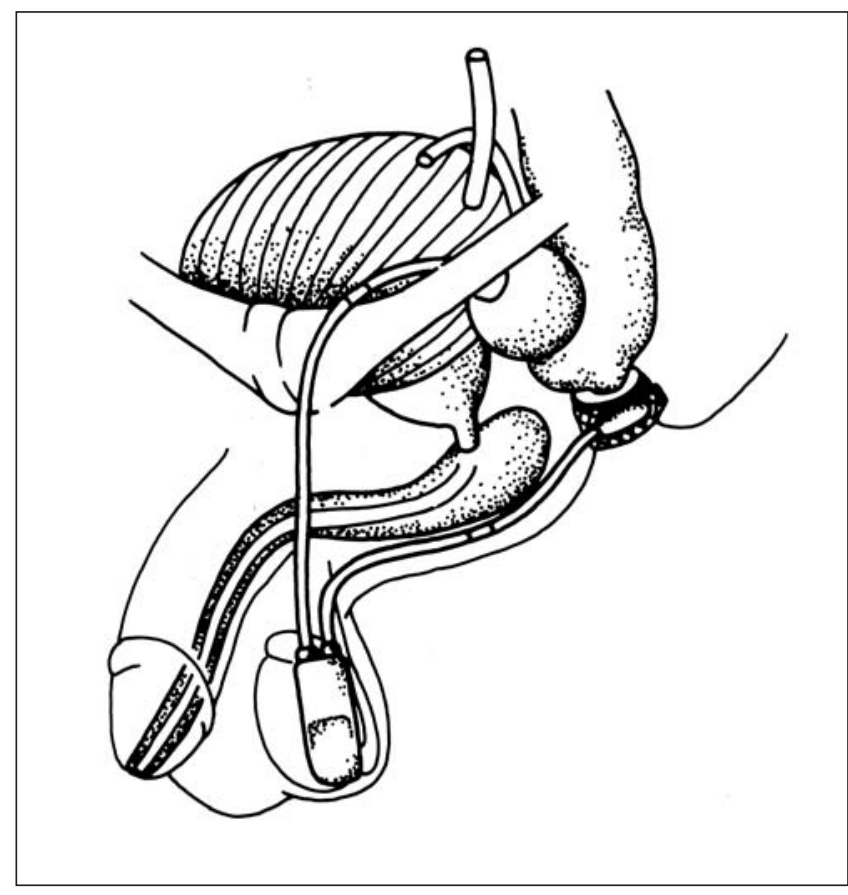

Figure 1) Artificial anal sphincter with the cuff placed around the anal canal, the pump in the scrotum and the pressure-regulating balloon to the left of the bladder

A pressure regulating balloon, which can produce a pressure up to $100 \mathrm{~cm} \mathrm{H}_{2} \mathrm{O}$, is placed extraperitoneally on the left or right side of the bladder. Through the same incision, the pump is placed in the scrotum or labium majus, and finally the three components are connected through subcutaneous tunnels with silicone tubings. The system is filled with a diluted radiopaque fluid. Defunctioning enterostomy was used routinely in only one of the published series (9). Perioperative antibiotic prophylaxis was given from two to five days after implantation.

\section{INDICATIONS AND RESULTS}

In the first published series (10), the main indication for implantation of an artificial anal sphincter was fecal incontinence due to neurological diseases, because other treatment options were not available for patients with incontinence of this etiology. In later series the indication was mainly the failure of other types of incontinence surgery and anal atresia. Primary implantation has also been performed in patients with severe traumatic destruction of the anal sphincter and in patients for whom local sphincter reconstruction was considered with no prospect of success (11).

An overview of the published series is given in Table 1 . All series are small, and follow-up in a number of patients was rather short. In the most recently published study (12), the median follow-up was 30 months. Approximately $80 \%$ of the patients have obtained a successful improvement of anal continence, but a number of revisions and reoperations have been necessary to reach this final result.

In the author's series (10) of patients who had an artificial sphincter implanted more than five years ago, half still have
TABLE 1

Published series on the treatment of fecal incontinence by implantation of the artificial anal sphincter

\begin{tabular}{lccc}
\hline Series (reference) & N & Improvement & Failure \\
\hline Christiansen et al (10) & 10 & 8 & 2 \\
Wong et al (9) & 12 & 9 & 3 \\
Lehur et al (11) & 10 & 9 & 1 \\
Vaizey et al (13) & 6 & 5 & 1 \\
Lehur et al (12) & 13 & 11 & 2 \\
\hline
\end{tabular}

the system functioning with a satisfactory result. As mentioned above, this series mainly consists of patients with incontinence due to neurological diseases, an especially difficult group to treat.

In those studies where anal manometry was performed both before and after the implantation, resting pressure increased markedly when the cuff was inflated, usually between $75 \%$ and $150 \%(10,11,13)$. No correlation between pressure increase and clinical result was demonstrated (11). The length of the functional anal canal was dependent on the width of the cuff used (which varied between 2 and $2.9 \mathrm{~cm}$ ), but no comparison with preoperative measurements was performed.

\section{COMPLICATIONS}

A number of complications have been reported in all studies. Implantation of foreign material in the anorectal region is likely to carry a higher risk of infection than implantation in other parts of the body, and infection has been a problem in all series, although to a lower degree than might have been expected. Explantation of the device due to infection varied between $15 \%$ and $17 \%$ in the different series (9-13). Preliminary results from an American multicentre trial gave an explantation rate due to infection of $23 \%$ (14). To reduce the infection rate, a meticulously perioperative regimen is necessary; it should include an effective antibiotic prophylaxis as well as strict attention to some technical details. It is essential that the cuff is placed around the anal canal in a such way that it does not slide down against the perineal skin and cause erosion. This is accomplished by placing the cuff above the anococcygeal raphe posteriorly and over the corresponding raphe or muscle anteriorly. In patients with anal atresia, these structures are often rudimentary and the cuff should be placed as high up as possible.

Rates of revisional surgery due to device-related complications vary between $40 \%$ and $60 \%$ (9-11). The complications mainly were rupture of the cuff or balloon and leakage of fluid from the system. Because the system is filled with a radiopaque fluid, rupture may easily be diagnosed by $\mathrm{x}$-ray (Figure 2).

Impaired rectal evacuation necessating enemas has been reported in $10 \%$ to $25 \%$ of the patients $(10,11)$. In the author's series (10), rectal evacuation problems were the reason for explantation in one patient. 


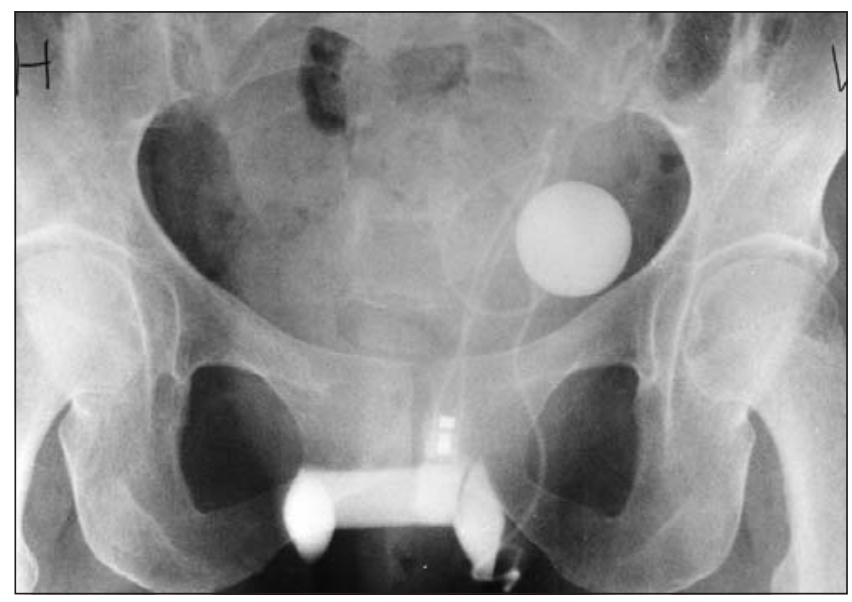

Figure 2) X-ray of a patient with sudden dysfunction after implantation of an artificial anal sphincter, showing the rupture of the closing mechanism of the cuff, which no longer encircles the anal canal

\section{DISCUSSION}

The artificial anal sphincter is one of the few options for treating end-stage fecal incontinence. The recent change of a system developed from a modified urinary sphincter to a specifically designed anal sphincter seems to reduce device-related complications. Infectious complications have been reduced in the most recent published series (12), while rectal evacuation problems still occur in a considerable number of patients. This disorder seems, however, to be managed well by enemas and laxatives (12).

The selection of patients is of the utmost importance. If the perineum is severely scarred from previous surgery or has

\section{REFERENCES}

1. Feshman JW, Dreznik Z, Fry RD, Kodner IJ. Anal sphincter repair for obstetrical injury: manometric evaluation of functional results. Dis Colon Rectum 1991;34:1061-7.

2. Wexner SD, Marchetti F, Jagelman DG. The role of sphincteroplasty for fecal incontinence reevaluated: a prospective physiologic and functional review. Dis Colon Rectum 1991;34:22-30.

3. Engel AF, Kamm MA, Sultan AH, Bartram CI, Nicholls RJ. Anterior anal sphincter repair in patients with obstetric trauma. Br J Surg 1994;81:1231-4.

4. Rasmussen $\bigcirc \varnothing$, Puggaard L, Christiansen J. Anal sphincter repair in patients with obstetric trauma: age affects outcomes. Dis Colon Rectum 1999;42:193-5.

5. Engel AF, Brummelkamp WH. Secondary surgery after failed postanal or anterior sphincter repair. Int J Colorect Dis 1994;9:187-90.

6. Baeten CGMI, Geerdes BP, Adang EM, et al. Anal dynamic graciloplasty in the treatment of intractable fecal incontinence. N Engl J Med 1995;332:1600-5.

7. Christiansen J, Rasmussen $\bigcirc \varnothing$, Lindorff-Larsen K. Dynamic graciloplasty for severe anal incontinence. Br J Surg 1998;85:88-91. been previously irradiated, the artificial sphincter probably should not be used. The same is true when the rectovaginal septum is very thin. In these patients dynamic graciloplasty is probably a better solution, because transplantation of a well vascularized muscle is a far more physiological procedure under these circumstances. Furthermore, a history of impaired rectal emptying probably is a predictor of a less satisfactory functional result, which, however, is also true for dynamic graciloplasty. Although the majority of patients with emptying problems after implantation of an artificial sphincter seems to accept the use of enemas and laxatives, there are some who, in view of their quality of life, will consider the treatment a failure. Because impaired rectal emptying also occurs after dynamic graciloplasty (7), this operation is not an alternative to the artificial sphincter in patients with a history of obstructed defecation before the development of anal incontinence. Sacral nerve stimulation (15), where no surgery in the anal region is performed, may be a better solution in these patients, but experience with the method is still very limited. Furthermore, according to current knowledge, it requires an intact external anal sphincter, which will limit its use for the group of patients who are candidates for an artificial sphincter.

The artificial anal sphincter is a valid therapeutic alternative for end-stage fecal incontinence in patients without severe perineal pathology. Paying strong attention to the risk of infection is still mandatory because this complication is responsible for the majority of failures. Device-related complications have been reduced considerably with the present modification of the system.

8. Christiansen J, Lorentzen M. Implantation of artificial sphincter for anal incontinence. Lancet 1987;ii:244-5.

9. Wong WD, Jensen LL, Bartolo DCC, Rothenberger DA. Artificial anal sphincter. Dis Colon Rectum 1996;39:1345-51.

10. Christiansen J, Spars $\varnothing$ B. Treatment of anal incontinence by an implantable prosthetic anal sphincter. Ann Surg 1992;215:383-6.

11. Lehur PA, Michot F, Denis P, et al. Results of artificial sphincter in severe anal incontinence. Dis Colon Rectum 1996;39:1352-5.

12. Lehur PA, Glemain P, Bruley des Varannes S, Buzelin JM, Leborgne J. Outcome of patients with an implanted artificial anal sphincter for severe anal incontinence. Int J Colorect Dis 1998;13:88-92.

13. Vaizey CJ, Kamm MA, Gold DM, Bartram CI, Halligan S, Nicholls RJ. Clinical, physiological, and radiological study of a new purpose-designed artificial bowel sphincter. Lancet 1998;352:105-9.

14. Spencer M, Wong W, Congilosi S, et al. Artificial anal sphincter: Preliminary results of a multicenter prospective trial. Dis Colon Rectum 1998;41:A15. (Abst)

15. Matzel KE, Stadelmaier U, Hohenfellner M, Gall FP. Electrical stimulation of sacral spinal nerves for treatment of faecal incontinence. Lancet 1995;346:1124-7. 


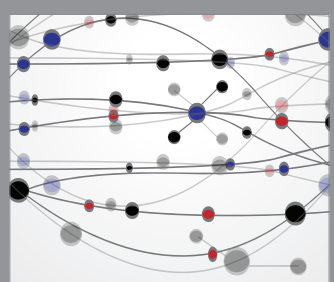

The Scientific World Journal
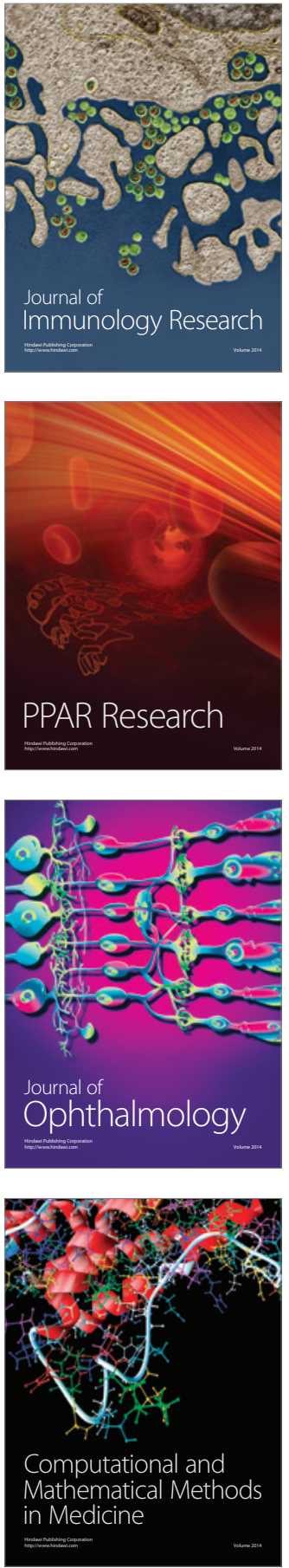

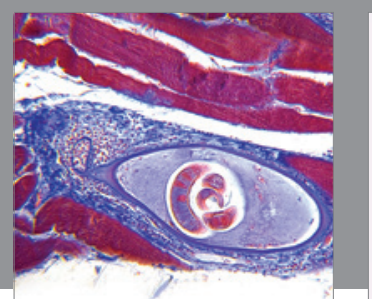

Gastroenterology Research and Practice

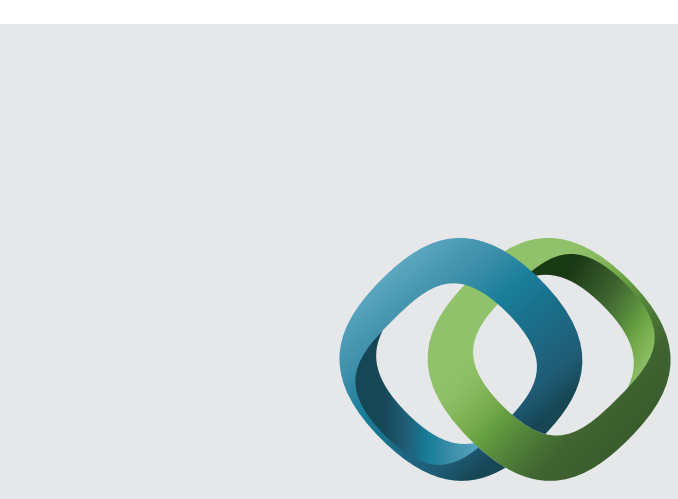

\section{Hindawi}

Submit your manuscripts at

http://www.hindawi.com
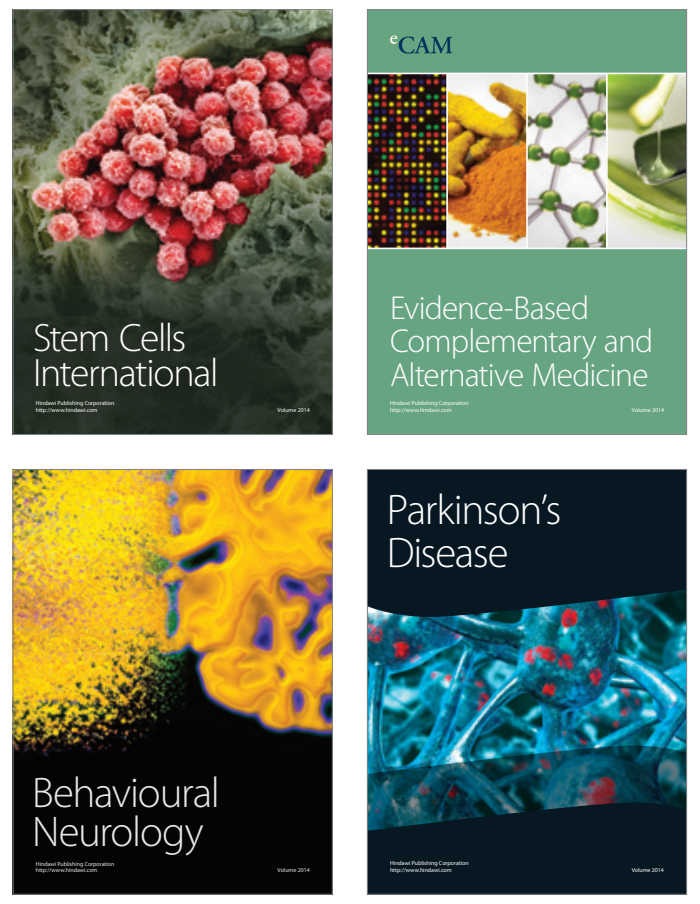
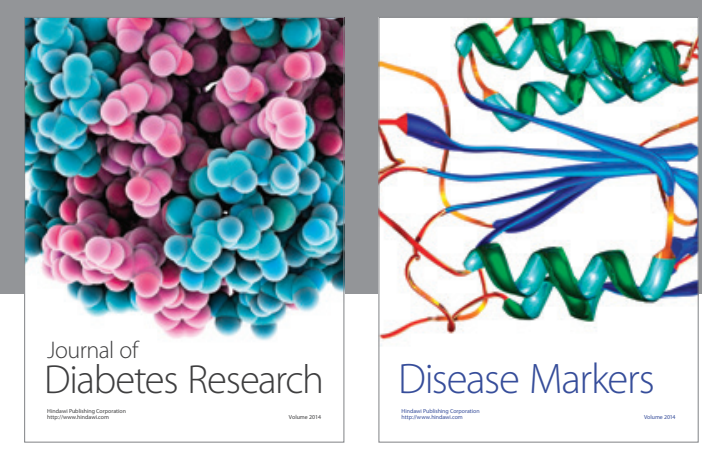

Disease Markers
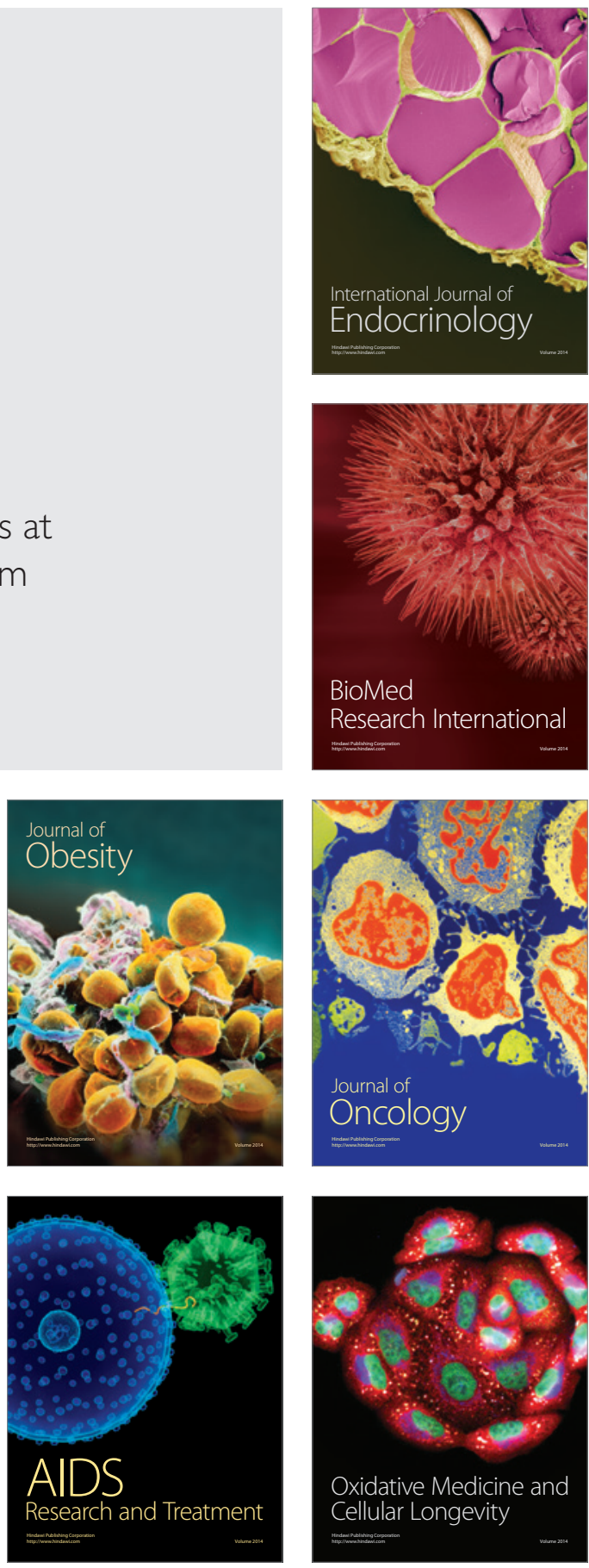